\title{
Assessment of Small Ruminant Haemonchosis and Its Associated Risk Factors in and Around Finoteselam, Ethiopia
}

\author{
Zelalem Mengist $^{1}$, Nigus Abebe ${ }^{1}$, Getachew Gugsa ${ }^{1}$ and Niraj Kumar ${ }^{1}$ \\ ('Mekelle University, College of Veterinary Medicine, Ethiopia)
}

\begin{abstract}
Haemonchus contortus a blood sucking nematode parasite of small ruminants across the tropics and subtropics causes an insidious drain on production, retarded growth and even mortality in young animals. A cross sectional study was conducted to determine the prevalence and associated risk factors of haemonchosis in randomly selected and slaughtered sheep and goats in four different restaurants in Finoteselam town, Amhara region. The study was performed on a total of randomly selected 397 small ruminants (37 sheep and 360 goats). A questionnaire survey, coprological examination, hematocrit $(P C V)$ determination and postmortem examinations were the methods used for this study. The overall prevalence in the current study was $71.03 \%$, while prevalence in sheep and goat were $67.57 \%$ and $71.39 \%$ respectively. The prevalence of haemonchosis with species difference of the animal was not statistically significant $(P=0.626)$. The infection rate with relation to sex $(P=0.102)$ and age $(P=0.603)$ were statistically non-significant. The prevalence of haemonchosis was higher in males (73.22\%) and adult animals (71.43\%). There was no statistical significant difference observed among the risk factors except the PCV value between sheep and goats which was statistically significant $(P=$ 0.000). The prevalence of haemonchosis in the study area was mostly associated with the epidemiological factors such as body condition and origin (collection sites) of animals and host factors such as species, sex and age.
\end{abstract}

Key words: Haemonchus contortus, prevalence, risk factor, small ruminants, Finoteselam, Ethiopia

\section{Introduction}

Ethiopia lies within the tropical latitudes of Africa and has an extremely diverse topography, wide range of climatic features and multitude of agro-ecological zones, which make the country suitable for different agricultural production systems. This in turn has contributed to the existence of a large diversity of farm-animal genetic resources in the country. The current livestock production of Ethiopia is estimated as 53.99 million heads of cattle, 25.49 million sheep, 24.06 million goats, 1.91 million horses, 6.75 million donkeys, 0.35 million mules, 50.38 million of poultry, 0.92 Million of camels and 5.21 million of bee hives [1]. Sheep and goats are among the major economically important livestock in Ethiopia. Ethiopian livestock production systems are broadly characterized as low input, mixed crop-livestock, agro-pastoral and pastoral systems; as well as medium input, peri- urban and urban enterprises. These livestock are almost entirely managed by the poor small-holder farmers and pastoralists [2].

Gastrointestinal (GI) nematode parasites are a major problem in most small ruminant production systems worldwide due to their impact on production and the cost of control measures undertaken by livestock producers. The problem of nematode parasitism is of particular importance throughout the developing world since nutritional resources available to small ruminant livestock are often inadequate and, as a consequence, natural immunity is compromised resulting in low productivity and high mortality [3]. Due to suitable geographic and climatic conditions of the country, parasitic GI nematodes are perhaps the leading cause of productivity losses in small ruminant production in Ethiopia [4]. Parasitological investigations carried out in different regions of the country have demonstrated the existence of a wide range of GI nematodes which belong to the genera Haemonchus, Trichostrongylus, Oesophagostomum, Bunostomum, Strongyloides, Cooperia, Bunostomum, Nematodirus and Trichuris species [5, 6, 2, 7]. H. contortus commonly known as the twisted stomach worm is a blood sucking nematode parasite, primarily occurring in the abomasum of small ruminants, notably sheep and goats. It has been ranked as the most important parasite of small ruminants in all regions across the tropics and subtropics and causes an insidious drain on production, retarded growth, loss of appetite, anemia, edema, decrease in protein and even mortality in young animals as reported by Paddock [8] and Bhat et al., [9] as well as the emerging anthelmintic resistance [10]. Essentially the pathogenesis of haemonchosis is that of an acute hemorrhagic anemia due to the adult haemonchus and fourth stage larvae puncture small blood vessels of the abomasal wall, feeding on the blood. Haemonchus is thought to inject an anticoagulant into the wound so that the host actually loses more blood or the worm ingest. Each worm removes about $0.05 \mathrm{ml}$ of blood per day by ingestion and seepage from the lesion. The pathogenesis of $\mathrm{H}$. contortus results from inability of the host to compensate for blood loss [11]. 
The disease caused by this parasite is prevalent wherever sheep and goats are raised, but it exerts the greatest economic losses in temperate and tropical regions [12]. The disease has also found in the colder climates and recently been found as far north as the Arctic Circle [13]. Economic losses are primarily due to mortality and loss in production and stunted growth, poor weight gain and poor fee utilization. It is a serious health problem, which causes lower production due to high morbidity and mortality and cost of treatment and control measures [14]. Despite the economic importance of this parasite and high population of small ruminants in the study area, limited work has been made on the epidemiology of small ruminant haemonchosis. Therefore, detailed information is crucial to develop control and prevention strategies. The objective of the present study was carried out to determine the current prevalence of small ruminant haemonchosis and to assess its potential risk factors in and around Finoteselam, Ethiopia.

\subsection{Study Area}

\section{Materials and Methods}

The study was conducted in Finoteselam, West Gojjam Zone of Amhara National Regional State (ANRS) which is situated at a distance of $376 \mathrm{~km}$ North West from Addis Ababa, the capital of Ethiopia and $185 \mathrm{~km}$ South of Bahir Dar, the capital of Amhara Regional State. This town has a longitude and latitude of $10^{\circ} 42^{\prime} \mathrm{N} 37^{\circ} 16^{\prime} \mathrm{E}$ with an elevation of 1917 meters above sea level (masl) and average annual rain fall of $1550 \mathrm{~mm}$.

\subsection{Source and Study population}

Small ruminants that are found in and around Finoteselam were selected as study animal were serving as study population. Ages of animals were determined by looking the dentition of the animal stated by [15]. Animal body condition score was also recorded using the criteria stated by [16].

\subsection{Study Design, Study Period and Sampling Method}

Cross sectional epidemiological study was conducted from November 2013 to April 2014 on randomly selected sheep and goats to determine the overall prevalence of haemonchosis in and around Finoteselam. Simple random sampling technique was employed.

\subsection{Sample Size determination}

The sample size (n) was anticipated using the statistical formula described by Thrusfield [17].

$$
\mathrm{n}=\frac{\mathrm{z}^{2} \mathrm{p}(1-\mathrm{p})}{\mathrm{d}^{2}}
$$

Where, $\mathrm{n}=$ minimum number of sample size, $\quad \mathrm{z}=1.96$ at $95 \%$ level of confidence

$\mathrm{d}=$ absolute precision, $\quad \mathrm{p}=$ expected prevalence

As an input, sample size was determined based on the previous prevalence done elsewhere in Amhara region (79.68\%) [18]. For calculation, a 95\% level of confidence (z) and a 5\% margin of error (d) were used. Based on the above formula the minimum desired sample size was 377 and so as to increase the accuracy of the study, 5\% of the above calculated sample size was added. Hence, the total sample size increased to 397.

\subsection{Study Protocol}

\subsubsection{Questionnaire survey}

A structured questionnaire format was prepared to obtain general information on age, sex, livestock ownership pattern, importance of small ruminant keeping, awareness of haemonchosis and their effect on small ruminant production and haemonchosis control practices exercised in the area.

\subsubsection{Coprological examination}

A few hours before slaughter ante-mortem investigation was performed and properly recorded for each animal concerning its origin, sex, age, body condition score and its general health condition. The fecal samples for parasitological examination was collected directly from the rectum of each sheep and goat using disposable gloves and placed in clean screw-capped universal bottle and each sample was clearly labeled. Faecal sample was preserved with $10 \%$ formalin solution to avoid the eggs developing and hatching. The laboratory technique was employed based on the detection or enumeration of nematode eggs per gram in the faeces by microscopic examination using the methods of flotation (e.g., McMaster chamber). The faecal egg counts (FECs) were expressed as number of eggs per gram fresh faeces. Intensity of infection using FEC was graded according to Hansen and Perry [19]. Accordingly, for degree of infection in small ruminants a FEC of 50-800 epg was considered a light infection, 800-1,200 epg a moderate infection and >1,200 epg a heavy infection. 


\subsubsection{Hematocrit (PCV) determination}

Blood samples were collected from the peripheral ear vein of each animal using heparinized microhaematocrit capillary tubes that filled $3 / 4$ of the height and sealed with crystal seal. The sealed microhaematocrit capillary tubes containing blood were centrifuged by microhaematocrit centrifuge for 5 minutes at 12,000 rpm. After centrifugation, the pack cell volume (PCV) value was recorded for estimation of anemia using Hematocrit reader [20].

\subsubsection{Sample collection for worm recovery}

The study was conducted on sheep and goats slaughtered in different restaurants in Finoteselam town. Four days per week visit was made to the purposively selected restaurants and a total of 397 abomasums were removed from their abdominal cavity and legated at both ends. The abomasum were collected usually within 30 minutes of evisceration and transported to parasitology laboratory within 30 minutes for confirmation of presence of adult H.contortus worms. Post mortem examination was conducted by a "total worm count", followed by the morphological identification of adult haemonchus parasite collected from the abomasal contents as described by Roberts and Swan [21]. The abomasums were opened along their greater curvature and the contents were washed into a bucket up to a total volume of 2 liters from which an aliquot of $200 \mathrm{ml}$ was transferred to a labeled graduated beaker and preserved in $10 \%$ formalin. A sub sample of $20 \mathrm{ml}$ was taken into a petridish for examination of abomasal worms under stereomicroscope. For those positive abomasal samples the number of worms were determined by multiplying $20 \mathrm{ml}$ (aliquot) X 100 (factor) and the degrees of infection was categorized as light (1- 500), moderate (501-1500) and heavy (greater than 1500) as described by Hansen and Perry [19].

\subsection{Data analysis}

A data base was developed to store quantitative data from the cross sectional study using Microsoft office Excel 2007 sheet and imported to statistical software. STATA version 11 was used to compute descriptive statistics of variables collected during the study period. Chi square was used to manipulate prevalence of $\mathrm{H}$. contortus across the potential risk factors. The odd ratio test was used to determine the strength of association between explanatory variables (sex, age, PCV, and origin and body condition) and haemonchosis. P-value $<0.05$ was reported as statistically significant.

\section{Results}

A total of 397 small ruminants (caprine $=360$ and ovine $=37$ ) from five local administrative units (kebele) were included in this study. $44.33 \%$ of study animals were from Dembecha while $40.30 \%$ were from Finoteselam. $89.92 \%$ of the study animals were adults (age greater than 1.5 years). $61.71 \%$ of the study animals had body condition score of three and with mean PCV value of 27.43 \pm 4.15 (mean \pm SD). The overall demographic data of study animals are summarized in the following table (Table 1).

Table 1. Distribution of study animals by demographic data

\begin{tabular}{|l|l|l|}
\hline Characteristics & Frequency & Percentage \\
\hline Sex of animal & & \\
Male & 295 & 74.31 \\
Female & 102 & 25.69 \\
\hline Species & & \\
Ovine & 37 & 9.32 \\
Caprine & 360 & 90.68 \\
\hline Age of animal & & \\
Young & 40 & 10.08 \\
Adult & 357 & 89.92 \\
\hline Collection site & & \\
Finoteselam & 160 & 40.30 \\
Dembecha & 176 & 44.33 \\
Burie & 19 & 4.79 \\
Genet & 18 & 4.53 \\
Jiga & 24 & 6.05 \\
\hline Body condition score & & \\
1 & 10 & 2.52 \\
2 & 94 & 23.68 \\
3 & 245 & 61.71 \\
4 & 42 & 10.58 \\
5 & 6 & 1.51 \\
\hline PCV value & & \\
Less than average & 283 & 71.28 \\
Average & 24 & 6.05 \\
Greater than average & 90 & 22.67 \\
\hline & & \\
\hline
\end{tabular}


Coprological and Postmortem examination: The current study reveals that the overall prevalence of haemonchosis in and around Finoteselam was 71.03\%. The following table (Table 2) shows that there was statistical significance $(\mathrm{p}=0.000)$ in the prevalence of haemonchosis both during coprological and post mortem examination in the study area.

Table 2. Chi square analysis of coprological and post mortem examination

\begin{tabular}{|l|l|l|l|l|}
\hline \multicolumn{2}{|c|}{} & \multicolumn{2}{|l|}{ Postmortem examination } & \multirow{2}{*}{ p-value } \\
\cline { 3 - 5 } & Positive & Negative & \\
\hline Coprological Examination & Positive & $282(71.03 \%)$ & $0(0.00)$ & \multirow{2}{*}{0.000} \\
\cline { 2 - 4 } & Negative & $0(0.00)$ & $115(28.97 \%)$ & \\
\hline
\end{tabular}

Figure-1 summarizes coprological and postmortem infection rate of haemonchosis. Out of 282 coprological positive animals, $13 \%$ had high infection rate.

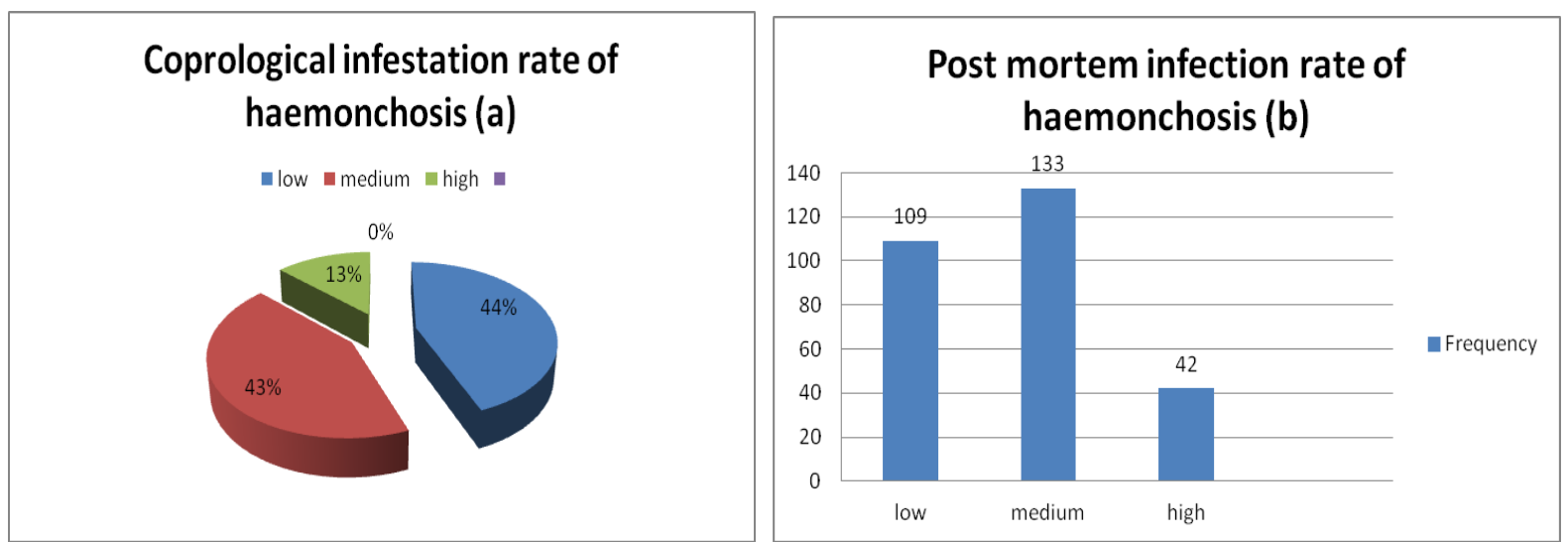

Figure 1: Coprological (a) and post mortem (b) infection rate of haemonchosis

An attempt was made to relate the impact of animal associated risk factor to the prevalence of the haemonchosis. Prevalence of $67.57 \%$ and $71.39 \%$ of haemonchosis was documented in sheep and goat, respectively which didn't have statistical significant difference $(\mathrm{P}=0.626)$. While the prevalence of haemonchosis in male and female small ruminants were $73.22 \%$ and $64.71 \%$ respectively. There was no statistical significant difference $(\mathrm{P}=0.102)$ in prevalence of the disease due to sex differences.

Age wise, the prevalence of haemonchosis in young and adult small ruminants was $67.5 \%$ and $71.43 \%$, respectively. There was no statistical significant variation $(\mathrm{p}=0.603)$ in prevalence of haemonchosis among age groups of animals.

There was statistical significant difference $(\mathrm{p}=0.000)$ across the $\mathrm{PCV}$ category versus the prevalence of the disease. Highest prevalence $(90.46 \%)$ was observed in animals that were having PCV value less than average. There was also statistical significant difference $(\mathrm{p}=0.009)$ in the prevalence of the disease among animals from 'Genet' with regard to the origin and body condition scores 4 (Fatty) ( $\mathrm{p}=0.008$ ) and marginal statistical significance $(\mathrm{p}=0.048)$ with body condition score of 5 (obesity).

Table-3 summarizes the results of logistic regression analysis associated with prevalence of haemonchosis and animal related risk factors. In multivariate logistic regression data analysis, animals that had less than the average PCV value remains statistical significance with animals that had average PCV value in relation to the prevalence of the infection (odds ratio $=18.31$ ).

With regard the source of animals from where they were collected, animals from Genet had highly significant difference on the prevalence of the infection ( $p=0.009$; CI: $1.546515-22.36693)$.

Table 3. Multivariate logistic regression analysis of predictors of haemonchosis

\begin{tabular}{|c|c|c|c|c|c|c|}
\hline \multicolumn{2}{|l|}{ Variable } & Odds Ratio & Std. Err. & $\mathrm{P}>|\mathrm{z}|$ & \multicolumn{2}{|c|}{ [95\% Conf. Interval] } \\
\hline \multirow[t]{2}{*}{ Sex } & Male & \multirow{2}{*}{$\begin{array}{l}1 \\
1.612014\end{array}$} & \multirow[b]{2}{*}{0.5916765} & \multirow[b]{2}{*}{0.193} & \multirow[b]{2}{*}{.7851315} & \multirow[b]{2}{*}{3.309751} \\
\hline & Female & & & & & \\
\hline \multirow[t]{2}{*}{ Age } & Young & \multirow{2}{*}{$\begin{array}{l}1 \\
1.050079\end{array}$} & \multirow[b]{2}{*}{.5645721} & \multirow[b]{2}{*}{0.928} & \multirow[b]{2}{*}{.3660799} & \multirow[b]{2}{*}{3.012092} \\
\hline & Adult & & & & & \\
\hline \multirow[t]{3}{*}{ PCV category } & Less than average & \multirow[t]{2}{*}{1} & \multirow[b]{3}{*}{$\begin{array}{l}9.492778 \\
61.37596\end{array}$} & \multirow[b]{3}{*}{$\begin{array}{l}0.000 \\
0.000 \\
\end{array}$} & \multirow[b]{3}{*}{$\begin{array}{l}6.627851 \\
48.59174 \\
\end{array}$} & \multirow[b]{3}{*}{$\begin{array}{l}50.58153 \\
327.3552\end{array}$} \\
\hline & Average & & & & & \\
\hline & Greater than average & $\begin{array}{l}18.30975 \\
126.122\end{array}$ & & & & \\
\hline \multirow[t]{3}{*}{ Origin } & Finoteselam & \multirow{3}{*}{$\begin{array}{l}1 \\
1.117223 \\
1.953304\end{array}$} & \multirow{3}{*}{$\begin{array}{l}.4265709 \\
1.456795\end{array}$} & \multirow{3}{*}{$\begin{array}{l}0.772 \\
0.369\end{array}$} & \multirow{3}{*}{$\begin{array}{l}.5286149 \\
.4528292\end{array}$} & \multirow{3}{*}{$\begin{array}{c}2.36124 \\
8.425681\end{array}$} \\
\hline & Dembecha & & & & & \\
\hline & Burrie & & & & & \\
\hline
\end{tabular}


Assessment of Small Ruminant Haemonchosis and Its Associated Risk Factors in and ....

\begin{tabular}{|c|c|c|c|c|c|}
\hline & Genet & 5.881394 & 4.008393 & 0.009 & $1.546515 \quad 22.36693$ \\
\hline & Jiga & 2.42898 & 1.614778 & 0.182 & $\begin{array}{ll}.660006 & 8.939229\end{array}$ \\
\hline \multirow{5}{*}{$\begin{array}{l}\text { Body condition } \\
\text { score }\end{array}$} & Emaciated & \multirow{5}{*}{$\begin{array}{l}1 \\
.7239828 \\
.326346 \\
.0691383 \\
.070173\end{array}$} & \multirow{5}{*}{$\begin{array}{l}.6335694 \\
.2822373 \\
.0699339 \\
.0942763\end{array}$} & \multirow{5}{*}{$\begin{array}{l}0.712 \\
0.195 \\
0.008 \\
0.048\end{array}$} & \multirow{2}{*}{$\begin{array}{l}4.02373 \\
1.777592 \\
.5020139 \\
.9766662\end{array}$} \\
\hline & Thin & & & & \multirow{3}{*}{$\begin{array}{l}.130265 \\
.0599135 \\
.0095219 \\
.0050419\end{array}$} \\
\hline & Moderate & & & & \\
\hline & Fatty & & & & \\
\hline & Obesity & & & & \\
\hline
\end{tabular}

*PCV category: average $24-45$ (ovine), $20-38$ (caprine)

Questionnaire Survey: Fifty respondents (male $=41$ and female $=9$ ) with mean age of 36 years (St. Dev. $=12.43 \mathrm{yr})$ were included during the questionnaire survey. Educational levels of respondents were summarized as $32 \%, 46 \%$, and $22 \%$ for illiterate, primary school and secondary school and above, respectively. $82 \%$ of the respondents were managing small ruminants mixed with other species of animals. People's knowledge and practices on animal health feature was found that almost all respondents do not know the endoparasite disease of small ruminant, mainly haemonchosis.

\section{Discussion}

The present study revealed an overall prevalence of $(71.03 \%)$ of haemonchosis which accounts $67.57 \%$ in sheep and $71.39 \%$ in goats. There was no significant difference $(\mathrm{P}=0.626)$ in the prevalence of haemonchosis between sheep and goats, indicating that both species are equally susceptible to the infection. This might be due to less awareness of the people about the disease haemonchosis. People's knowledge and practices on animal health feature was found that about $78 \%$ of respondents were elementary and below education level. This might have an impact on the high prevalence of haemonchosis. $82 \%$ of the respondents were managing their small ruminants mixed with other species of animals. $86 \%$ of the respondents were found to use modern treatment. $38 \%$ of respondents were gave responses that adult age groups were more affected by the disease.

In the previous studies, various workers reported variable prevalence rate of haemonchosis in different geographical areas. However, the prevalence may vary from country to country and even within the country. The overall prevalence of haemonchosis $(71.03 \%)$ in the present study area was lower than the previous studies reported by different researchers from Ethiopia and different parts of the world to be $96.5 \%$ prevalence in sheep and $100 \%$ in goats in the arid and semi-arid zone of eastern Ethiopia [5]; 91.2\% prevalence reported in sheep and $82.9 \%$ in goats in Ogaden region slaughtered at Debre-Zeit ELFORA abattoir [22]; 81.1\% prevalence reported in small ruminants in Awasa [23]; 79.68\% (81.35\% in sheep and 72.6\% in goats) reported in Komobolcha town [18]; 77\% reported in small ruminants in Kenya [24]; 78\% reported in small ruminants in Heilongjiang [25] and $80.64 \%$ reported in small ruminants in Pakistan [26].

The prevalence of the current study is lower than the previous studies, still it is a high prevalence of haemonchosis in the study area. This might be due to the fact that sheep and goats are managed under extensive system with the high stocking density, where large numbers of animals graze together throughout the year, inadequate nutritional status and poor veterinary services. The other plausible explanation for high prevalence may also be due to the existence of a direct relationship between prevalence and rainfall, humidity and temperature. That means the presence of sufficient rainfall and moisture during the study period was favored the survival of infective larvae in pasture and higher probability of uptake of the infective larvae leading to higher prevalence rate

Present study revealed that there was no significant difference based on sex $(\mathrm{P}=0.102)$ and age $(\mathrm{P}$ $=0.603$ ) with the prevalence of $73.22 \%$ and $64.71 \%$ in males and females and $67.50 \%$ and $71.43 \%$ in young and adults respectively. All age groups of sheep and goats are susceptible to haemonchus species infection and most of the researchers have observed higher rate of haemonchosis in young [27, 28], the prevalence of haemonchosis was higher in adults in the present study. This is probably due to the facts that adults might be stressed on seasonal change and developed resistance against the frequently used anthelminthic; while the young ones might be respond to anthelminthic that minimizes their infection rate.

There was a relationship between EPG count and the number of adult $\mathrm{H}$. contortus parasite present in the host abomasum. Hence conditions in the external environment were favorable for parasite development and survival, in which case eggs were produced by worms and excreted in the faeces.

Relationship between body condition and haemonchosis in sheep and goats was recorded with no statistical difference between emaciated, thin and moderate body conditioned animals, which means those animals were equally susceptible for haemonchosis which disagrees with previously reported by Tasawar et al. [29]. This could be explained by the fact that loss of body condition in the study animals could be due to other factors, such as seasonal change of forgeable feed staff and the presence of other concurrent diseases.

During the study period, the highest prevalence of haemonchosis was recorded in those animals brought from Dembecha (75.57\%); while the lowest prevalence was recorded in the animals that brought from Genet $(61.11 \%)$. This might be due to the environmental factors (temperature and humidity) those facilitates the 
distribution of the parasite to the grazing pasture because of the geographical area which is easy predisposing with flood especially during the rainy season. This study showed the occurrence of infection of small ruminants of the area by abomasal nematodes suggesting the existence of pasture contamination and the availability of infective larvae during months of the study period.

\section{Conclusion}

The prevalence of haemonchosis in this study area is mostly associated with the epidemiological factors such as origin of the animals and host factors such as sex and age. The epidemiological evidence of the present investigation showed that haemonchosis is considerably prevalent diseases in the study area. Generally, the presence of risk factors like warm and humidity, poor animal management, and seasonal change leads to feed stress and other concurrent diseases in the study area favors the distribution of disease.

\section{Acknowledgements}

The authors are grateful to Dean and Head, College of Veterinary Medicine as well as community people of study area for general support during this study.

\section{References}

[1] CSA. 2012/13. Agricultural sample survey. Report on livestock and livestock characteristics. The Federal Democratic republic of Ethiopia, Central Statistical Agency (CSA). Private Peasant Holdings. Statistical Bulletin 570, Addis Ababa, Ethiopia, April, 2013.

[2] Sissay, M., Uggla, A. and Waller, P. 2007. Prevalence and Seasonal Incidence of Nematode Parasites and Fluke Infections of Sheep and Goats in Eastern Ethiopia. Global veterinary, 2: 46-91.

[3] Perry, B., Randolph, T., McDermott, J., Sones, K.R. and Thornton, P. 2002. Investing in Animal Health Research to Alleviate Poverty International Livestock Research Institute, Nairobi, Kenya, p. 148.

[4] Biffa, D., Jobre, Y. and Chakka, H. 2007. Ovine Helminthosis, a Major Health Constraint to Productivity of Sheep in Ethiopia. Animal Health Research Reviews, 7(1/2), 107-118.

[5] Abebe, W. and Esayas, G. 2001. Survey of Ovine and Caprine Gastro-Helminthosis in Eastern part of Ethiopia during the Dry Season of the Year. Medical Veterinary, 152: 379-384.

[6] Asha, A. and Wossene, A. 2007. Gastrointestinal Ttract Nematodosis of Small Ruminants in Three different Agro-Ecological Zones in Southern Ethiopia. Ethiopian Veterinary Journal, 11(1), 83-94.

[7] Smith, B. 2009. Large Animal Medicine ( $4^{\text {th }}$ Ed.). Netherlands: Kluwer Academic Publishers, Pp: 1447-1449.

[8] Paddock, R. 2010. Breed, Age and Sex Wise Distribution of Haemonchus contortus in Sheep and Goats in and around Rawalpindi Region, Pakistan. Medical Veterinary Journals, 12: 60-63.

[9] Bhat, S., Mir, M., Allaie, S., Khan, H., Husain, I. and Ali, A. 2011. Comparative Resistance of Sheep Breeds to Haemonchus contortus in Pasture Infection in Jammu and Kashmir. Global veterinaria, 8: 222-228.

[10] Scheuerle, M. 2009. Anthelmintic Resistance of Haemonchus contortus and the Famacha Method as a Tool to Delay the Development of Anthelmintic Resistance ( $1^{\text {st }}$ Ed.). Pp: 17-20.

[11] Taylor, M., Coop, R. and Wall, R. 2007. Veterinary Epidemiology ( ${ }^{\text {rd }}$ Ed.). Black well, Asia. P. 159

[12] Chaudhary, R., Khan, F. and Qayyum, M. 2007. Prevalence of Haemonchus contortus in Naturally Infected Small Ruminants Grazing in the Potohar Areas of Pakistan. Veterinary journal, 2: 73-79.

[13] Durrani, Z., Kamal, N. and Khan, S. 2007. Sero-diagnosis of Heamonchosis in Small Ruminants. Global veterinary, 1: 01-66.

[14] Tariq, K., Chishti, M., Ahmad, F. and Shawl, A. 2008. Epidemiology of Gastro Intestinal Nematodes of sheep Managed under Traditional Husbandry System in Kashmir Valley. Veterinary parasitology, 158: 138-143.

[15] Gatenby, R. 1991. Sheep: in the Tropical Agriculturalist, Macmillan Punishing Company, New York. Pp. 6-10.

[16] Suiter, J. 2006. Body Condition Scoring of Sheep and Goats. Farm note, Sheep Industries Branch, South Perth.

[17] Thrusfield, M. 2005. Veterinary epidemiology ( ${ }^{\text {rd }}$ Ed.). Singapore, Black well Science, p: 233.

[18] Ketama, E., Fentahun, T. and Chanie, M. 2011. Small Ruminant Haemonchosis is a serious nematode parasite in Slaughtered at Kombolcha Slaughter Houses. IJAVMS. Online First, 16 Dec, 20011. (doi.10.5455/ijavms.13000)

[19] Hansen, J. and Perry, B. 1994. The Epidemiology, Diagnosis and Control of Helminth Parasites of Ruminants. A hand book International Laboratory for Research on Animal Disease (ILRAD), Nairobi, Kenya. Pp: 158-168.

[20] Coffin, D. 1995. Manual of Veterinary and Clinical Pathology ( ${ }^{\text {rd }}$ Ed.). Comst. Pub.Ass.Inc. Ithaca.New York.

[21] Roberts, J. and Swan, R. 1981. Quantitative Studies of Ovine Haemonchosis. Relationship between Fecal Egg counts and Total Worm counts. Veterinary Parasitology, 8(2):165-171.

[22] Kumsa, B. and Wossene, A. 2006. Abomasal Nematodes of Small Ruminant of Ogaden Region, Eastern Ethiopia: Prevalence, Worm Burden and Species Composition. Revue Médical Veterinary Journals, 157: 27-32.

[23] Thomas, N., Teshale, S. and Kumsa, B. 2007. Abomasal Nematodes of Sheep and Goats Slaughtered in Awasa, Ethiopia. Medical Veterinary Journal, 2:70-75.

[24] Githigia, S., Thamsborg, S., Munyua, W. and Miangi, N. 2001. Impact of Gastrointestinal Helminthes on Production in Goats in Kenya. Small Ruminant Research, 42: 21-29.

[25] Wang, C., Qiu, J., Zhu, X., Han, X., Ni Zhao, H., Zhou, Q., Zhang H. and Lun, Z. 2006. Survey of Helminths in Adult Sheep in Heilongjiang province, People's Republic of China. Veterinary Parasitology, 140: 378-382.

[26] Asif, M., Azeem, S., Asif, S. and Nazir, S. 2008. Prevalence of Gastrointestinal Parasites Sheep and Goats in and around Rawalpindi and Islamabad, American-Eurasian Journal of Scientific Research, 2: 05-12.

[27] Gauly, M., Schackert M., Hoffmann, B. and Erhardt, G. 2006. Influence of Sex on the Resistance of Sheep Lambs to an Experimental Haemonchus contortus infection. Dtsch. Tierarztl. Wochenschr.113: 178-181.

[28] Kuchai, J., Chishti, M., Manal, M., Ahmad, J., Rasool, M., Dar, S. and Tak, H. 2011. Prevalence of Nematode Parasites in Sheep of Ladakh - American-Eurasian Journal of Scientific Research, 4: 59-63.

[29] Tasawar, Z., Ahmad, S., Lashari, M. and Hayat, C. 2010. Prevalence of Haemonchus contortus in Sheep at Research Centre for Conservation of Sahiwal Cattle (RCCSC) Jehangirabad District Khanewal, Punjab, Pakistan. Pakistan J. Zool., Vol. 42(6):735-739 